\title{
QUANDO A FICÇÃO SE RECORDA, QUANDO O SENTIDO PASSA A RESISTIR
}

\author{
Michel RiAudel \\ TRADUÇÃO DE Milton OHATA
}

\begin{abstract}
RESUMO
A partir de três narrativas da literatura brasileira contemporânea, este ensaio examina como a ficção memorialística se desdobra em função do grau e do tipo de fragmentação narratológica: Relato de um certo oriente, de Milton Hatoum, trabalha com as reverberações da difração cultural; Resumo de Ana, de Modesto Carone, com as divergências do contraponto; O motor da luz, de José Almino, com uma subjetividade despedaçada e polifônica. Da mesma forma, o uso da referência literária discrimina nessas obras três posturas diante do conceito de literatura.
\end{abstract}

PALAVRAS-CHAVE: Memorialismo; narratologia; intertextualidade; literatura.

\section{ABSTRACT}

From three narratives of the contemporary brazilian literature, this essay investigate how the memorialistic fiction diversifies itself according to the level and the kind of narratological fragmentation: Relato de um certo oriente by Milton Hatoum operates with the reverberations of the cultural diffraction; Resumo de Ana by Modesto Carone with the divergences of the counterpoint; O motor da luz by José Almino with some exploded and polyphonic subjectivity. In the same way, the use of the literary reference discriminates in these three works three positions relating to the concept of literature.

KEYWORDS: Memorialism; narratology; intertextuality; literature.

[1] Hatoum, Milton. Relato de um certo oriente, São Paulo: Companhia das Letras, 1989; Almino, José.O motor da luz, Rio de Janeiro: 34 Letras, 1994; Carone, Modesto. Resumo de Ana, São Paulo: Companhia das Letras, 1998. Esses três romances foram traduzidos para o francês: Hatoum. Récit d'un certain orient, tradução de Claude Fage e Grabriel Iaculli, Paris: Seuil, 1993; Almino. Les Nôtres, tradução de Michel Riaudel, Paris: Maisonneuve e Larose, 2005; Modesto. Résumé d'Ana, tradução de Michel Riaudel, Paris: Chandeigne, 2005 .

[2] Marcondes, Marleine Paula e Toledo, Ferreira de, com a colaboração de
Em menos de dez anos, surgiram no Brasil três narrativas ficcionais nas quais o dispositivo de enunciação, sem que constituam "memórias" autênticas, parece todavia, nos três casos, resultar de um certo trabalho da recordação: Relato de um certo oriente, O motor da luz e Resumo de Ana ${ }^{1}$. Relato de um certo oriente, primeiro romance de Milton Hatoum, e Resumo de Ana, de Modesto Carone, foram saudados pela crítica, em comentários e artigos, sendo que o primeiro ensejou até mesmo duas exegeses ${ }^{2}$; os dois livros foram agraciados com o importante prêmio Jabuti, no ano que seguiu sua publicação; foram mais tarde adotados no programa de diversos concursos relacionados com os estudos literários ou ao ensino de literatura.Sem dúvida mais desconcertante, O motorda luz de JoséAl- 
mino foi mais discretamente acolhido 3 mas, a meu ver, nem por isso deixa de representar outra obra-prima cujas qualidades a legitimam como a terceira ponta de um triângulo que circunscreve, na literatura brasileira contemporânea, um espaço romanesco fecundo, situado entre ficção e autobiografia, relato e memória. Longe de representar certa produção narrativa, muito preocupada (entre outras formas e temáticas) com uma certa "atualidade" urbana, articulando violência e exclusão social, essas três prosas assinalam uma polaridade própria que merece ser analisada, tanto pelas convergências que esboçam como pela singularidade dos projetos que flexionam.

O primeiro fato notável que as caracteriza diz respeito precisamente à escolha da ficção pelos três autores. Se cada qual bebe abundantemente em sua experiência pessoal, geracional e familiar, navega em águas contíguas à biografia ou à autobiografia, pelo que não cede jamais à escrita documentária. O ponto de vista "memorialístico" não é senão de um caráter mimético, imitativo, a escolha romanesca ${ }^{4}$ dispensando os fatos "relatados" de uma exatidão histórica absoluta, de uma fidelidade implacável ao real. Num tempo em que parece decair a credibilidade da fábula e do imaginário, em que triunfam os livros-testemunho, de entrevistas, as reportagens, as biografias de todo tipo 5 , optar pela ficção vai quase à contracorrente dos critérios de sucesso editorial. Desordem de um mundo em recomposição? Inquietações apocalípticas? Todavia, eis que parece triunfar, em detrimento dos questionamentos próprios à aventura literária, o neopositivismo utilitarista das sínteses práticas, a aposta mais alta da verdade nua e crua e o reconforto mágico das "lendas pessoais". Ora, quer se trate de fornecer chaves pretensamente objetivas, de brutalizar por um naturalismo sempre mais radical ou de fornecer amuletos, a causa é afinal a mesma: a imediaticidade de respostas de curto prazo conjurando o sentimento de um desregramento, de desregulagens ou perdas de pontos de referência, em meio a uma concepção do real das mais limitadas. Sem dúvida, Milton Hatoum, José Almino e Modesto Carone pensam que autores eleitores têm mais a perder ao renunciarà elaboração simbólica do que ao sucumbir às sereias do fast book: escrito às pressas, lido às pressas. No jogo literário das máscaras e desvios, nada é seguro senão o incerto; mas o verdadeiro engodo não ficaria do lado do texto consumível, cuja natureza conveniente tranqüiliza, agrada, pelo tempo que dura a mistificação?

Ficções, portanto, com suas pregas, seus meandros, reciclando contudo as trajetórias individuais. Milton Hatoum bebe na odisséia da imigração sírio-libanesa, da qual participaram seus pais e avós ao longo do século XX. Tanto o pano de fundo como a aposta semântica de sua história se alimentam dos entrechoques culturais orientais e ameríndios ao se aculturarem, se aclimatarem no seio do cadinho oci-
Heliane Aparecida Lonti Mathias. Entre olhares e vozes: foco narrativo e retórica em Relato de um certo oriente $e$ Dois irmãos de Milton Hatoum. São Paulo: Nankin, 2004. Idem. Milton Hatoum: itinerário para um certo relato. São Paulo, Ateliê, 2006. Encontra-se no final desses livros uma bibliografia que dá a medida da recepção do romance.

[3] Destaquemos, no entanto, o ensaio que Vilma Arêas dedica a cinco narrativas, entre as quais a de José Almino e Modesto Carone. Ver "Narrativas de la experiencia (aproximación a $A$ hora da estrela, $O$ motor da luz, $A$ doença - uma experiência e Resumo de Ana". Revista de filologia románica. Madri: Universidad Complutense, Anejo II, 2001.

[4] Aqui, deixaremos de lado a discussão, inteiramente digna de interesse, sobre o gênero a que pertence Resumo de Ana, composto de duas novelas, mas que têm muito a ver uma com a outra por serem eventualmente lidas como um todo e, porta

[5] Ver Galvão, Walnice Nogueira. As musas sob assédio: literatura e indústria cultural no Brasil. São Paulo: Editora Senac, 2005, particularmente o cap. 3, "Um novo biografismo", pp. 97-119. 
dental amazônico. Filho de Miguel Arraes, governador progressista de Pernambuco, destituído e preso pelos militares em 1964, José Almino concentra-se sobre o período em torno do golpe de Estado, os anos de formação do narrador, o exílio, o retorno, mas evoca também suas origens familiares, nos confins do Ceará e de Pernambuco. O motor da luz acaba assim por abranger um período bem mais amplo que os anos de 1960, remontando até, por exemplo, ao célebre escritor romântico José de Alencar ou ao crítico Araripe Jr., entrevistos como que acidentalmente no texto. Quanto a Modesto Carone, narra o essencial de duas existências, a de Ana, que se confunde em grande parte com a de sua avó, e a de Ciro, que incorpora os traços do tio materno do escritor. Através das peripécias de seus percursos desfila um século de história brasileira, da abolição da escravatura proclamada em 1888 aos sobressaltos econômicos do regime militar instalado em 1964 e mesmo para além dele. Ana aprenderá a criar uma carapaça no seu trabalho como empregada doméstica, sua sede de emancipação e de ascensão social fará com que se case com um modesto padeiro de origem franco-italiana. Ciro percorrerá toda sua vida em busca de um bem-estar muitas vezes entrevisto e que sempre lhe escapará. Mesmo seu enterro, em 1990 , terá qualquer coisa de desajeitado, pois seu corpo será sepultado numa cova que não lhe fora destinada.

Estes três substratos familiares serão, todavia, remodelados em graus diversos que não importa por ora precisar. Em função do que julgam ser as necessidades de suas narrativas, Milton Hatoum, Modesto Carone e José Almino recompõem a realidade que conheceram ou de que ouviram falar, condensam destinos, forjam novos personagens, redistribuem anedotas, ajustam detalhes, inventam acontecimentos. A coerência ficcional importa mais do que a veracidade dos fatos. É ela que determina notadamente a escolha do dispositivo narrativo de vocação memorialista. Deste caráter retrospectivo da narrativa em primeira pessoa provém um desdobramento temporal: o plano pretérito dos acontecimentos narrados e o presente da enunciação. A diegese unifica-se sob os auspícios de uma subjetividade central, com todos os riscos possíveis de uma tal parcialidade. O narrador (narradora, no caso de Relato de um certo oriente) tem nas mãos todas as cartas da história, que nos entrega senão passo a passo, à medida de "sua" lógica. Entretanto, à tensão dramática que supõe a intriga (no plano do enunciado), se junta uma dissonância narrativa dominada pela visão lacunar do narrador, que deve recorrer em cada uma das três obras a vozes de reserva.

Desdeentão a univocidade da narração se quebra na multiplicidade de fontes narrativas. Fruto de diversas difrações, o relato apresenta-se como um tipo de tentativa de reparação de uma realidade estilhaçada, o assemblage mais ou menos acabado de uma série de fragmentos. O romance tem algo de quebra-cabeça, resultante, de um lado, das suspei- 
tas que pesam sobre a possibilidade de uma "verdade" histórica e, de outro, de uma explosão do "sujeito". O mergulho no passado assume aqui, em parte, as funções da descida aos infernos na epopéia antiga: consulta aos mortos, contato com uma experiência que não pode ser transmitida, busca das origens, interrogação identitária. A mimética memorialista, com suas linhas mais ou menos retas, investe-se, em parte, do valor etiológico do mito de fundação. Um tipo de romance de formação no passado, sem dele exatamente emprestar a virtude iniciática, mas compartilhando com ele uma certa pretensão teleológica: o ponto de chegada possível é esclarecido pelo discernimento da própria origem, da reorientação desejável do percurso familiar. Édipo, assim como outros, viveu por nós essa experiência.

Para além dessas convergências narratológicas entre esses três livros, a relação estabelecida entre o narrador principal e suas "delegações" deixa porém aparecer, mais do que variantes, divergências de fundo próprias, para em parteinstruiro projeto "estético-político" que lhe é subjacente.

Em Relato de um certo oriente, foi sublinhada a polifonia narrativa ${ }^{6}$, que se desdobra em uma arquitetura sofisticada: a narrativa-enquadramento da narradora anônima, endereçada a seu irmão que vive na Espanha; e as narrativas internas, intercaladas de maneira aproximadamente simétrica, que estruturam com a elegância da imperfeição a divisão em capítulos. Surge primeiramente a versão de Hakim, designado como o "tio" no seio da família que adotou e criou o par emissordestinatário; depois, Hakim dá lugar a Dorner, um amigo fotógrafo alemão, que por sua vez faz eco às confidências do pai de Hakim, patriarca não nomeado. A partir daí, a palavra volta novamente a Dorner, e depois a Hakim, antes que o relato da narradora venha fechar o ciclo, de passagem alimentado pelo testemunho de uma pessoa próxima da matriarca Emilie, Hindié Conceição. Ora, o que mais impressiona, nessa variedade de vozes que marcam as diferenças sociais, os desvios de parentesco, as origens diversas, são menos as desafinações que a complementaridade e as similitudes, tanto temáticas como formais. Mais fractais que fratura, elas são a expressão de protagonistas em posição lateral aos dramas centrais: o conflito que opõe o pai à sua mulher, o suicídio de Emir, irmão de Emilie. Personagens dignos de Euclides da Cunha e de Walter Benjamin, os narradores vivem à margem da intriga, como se o progresso da história os deixasse, bem como sua enunciação circular, à beira do caminho. Tempo linear contra tempo cíclico. A maioria tem, além do mais, uma origem "estrangeira", os libaneses, o alemão, a criança adotada. Mesmo a palavra central, nodal, do patriarca, e portanto o pilar da diegese, não o leva em consideração senão no momento de sua chegada a Manaus, ou seja, quando ele é ainda, provisoriamente, menos ator que observador.
[6] Ver, por exemplo, além das leituras de Marleine Paula Marcondes e Ferreira de Toledo já assinaladas, as de Maria Zilda Ferreira Cury: entre outras, "Récits d'immigrants". Quadrant, $\mathrm{n}^{\circ}$ 18, 2001, pp. 117-131; e “L'étranger qui m'habite: voix immigrants dans la fiction de Milton Hatoum", Quadrant, n 21, 2004, pp. 159-169. 
O dispositivo não leva nem à anulação recíproca dos pontos de vista, nem a uma constatação relativista que paralisaria os julgamentos. Ao contrário, os testemunhos se somam, os ângulos se cruzam para fazer de certo modo um desvio do real. O sistema narrativo é ele próprio um microcosmo, representativo de ao menos três gerações, de uma pluralidade religiosa, de toda uma paleta de sensibilidades e afinidades... Longe de exacerbar as contradições, o reflexo das escritas exalta a arte da tecelagem (e da mestiçagem) cultural: à maneira da tapeçaria oriental, de um Líbano onde coexistem cristãos maronitas e muçulmanos, da projeção mediterrânea sobre a Amazônia, da aculturação em processo entre as mulheres... Esboça-se assim uma das linhas de força do romance, interessado por aquilo que institui a dimensão cultural do homem, de uma região, de uma nação..., que ele concebe como aberta e movediça.

Essa harmonia é, entretanto, ameaçada pelas compartimentações, as hierarquias, as relações de dominação. Ela se escora nos silêncios e nos não-ditos para os quais se precipita a intriga: o emparedamento simbólico do pai em relação às práticas sacrílegas de sua mulhere suas amigas, o mutismo de Soraya Ângela, a criança indesejada, a que se esconde, o afogamento de Emir, mas também, mais longe, o recalcamento do que impeliu Emilie para o convento de Ebrin, e sobre aquilo que a afastou. Tais segredos ressoam por sua vez nos "esquecimentos", nas "reticências" dos protagonistas: a cegueira temporária do fotógrafo Dorner, a peça onde se recolhe Emilie, o cofre de que ela não se separa, os esconderijos de La Parisienne... Esses buracos negros, esses enigmas cristalizados no apagamento do nome-do-pai (que tem como réplica aquele da narradora) tal o nome impronunciável de Deus, acionam o esforço de investigação e de memória, justificam o trabalho da escrita. O escrito, a letra, o significante, são aqui ao mesmo tempo o que preserva o traço e assinala a perda, o meio e o lugar da refundação do "viver junto".

A narrativa memorialista de Modesto Carone é movida por uma força de certa maneira inversa. No relato, uma voz desdobrada em vozes parecidas nos leva de algum modo, ao longo de sua errância, dos outros ao mesmo, à relevação de um si-mesmo; aqui a homogeneidade aparente do narrador, idêntica de uma novela à outra, é na verdade minada a partir do seu interior, tornando-se o lugar de tensões que comprometem a unidade enunciativa. Primeiro porque aquele que assume a narrativa o faz em nome de uma dupla motivação, de um duplo estatuto: sua relação de parentesco e sua formação superior. Neto de Ana e sobrinho de Ciro, sua proximidade familiar confere ao texto empatia, insufla um lirismo contido que indiretamente convida o leitor à compaixão. Em compensação, sua personalidade está afastada das demais personagens por seu nível de instrução, que introduz uma distância 
quase objetiva, permitindo-lhe traçar um paralelo entre a diegese e a história do país, imprimir às relações sociais um valor antropológico. É essa combinação de observação e de participação que confere ao livro sua riqueza de tons. Assim a impressão de secura — condensada ilusoriamente pelo projeto de "resumo" - se interpreta igualmente como uma impassibilidade necessária à ambição "científica" da escrita (o observador) tanto como do pudor (o neto).

A este duplo horizonte ajusta-se o deslocamento da parentela que muda consideravelmente o ponto de vista. A história de Ana é transmitida em linha direta pela mãe do narrador, dona Lazinha (o mesmo nome ao qual é dedicada a novela: índice entre outros das coincidências possíveis entre o real e a ficção). A despeito das reticências, das reservas, das lacunas, essa narrativa faz parte da herança recebida pelo narrador e revela uma solidariedade bastante fusional entre mãe e filha. Ao longo de uma transmissão oral recolhida e consignada até o $3^{\circ}$ grau, as duas mulheres ajustam cada qual seu próprio filtro ótico, de maneira que tudo é percebido na primeira das duas novelas por meio de uma inflexão tripla na trama narrativa, nos contornos freqüentemente deslocados uns em relação aos outros. Eles agem por efeitos de distorção que não aparecem com clareza senão nas primeiras páginas de "Ciro", a novela seguinte. Dado que a história de uma mãe é parcialmente contemporânea da de seu filho, as narrativas se sobrepõem, certos motivos se repetem. Ora, é graças a essas ligações aparentes, felizmente mal ajustadas, que o leitor compreende como a simpatia do olhar vai doravante ser deportada das personagens femininas aos homens da família. Já que as incompatibilidades entre Ana e Balila foram transferidas às crianças, as duas, filhos do casal, aderem ao destino de sua mãe, não somente contra o pai, mas também contra o irmão, afastado de sua aliança por meio de intrigas ao longo de toda a sua vida. Sem hostilidade nem ressentimento em relação a suas irmãs, Ciro, na novela epônima que lhe é dedicada e se aproxima de seu ponto de vista, nos faz descobrir involuntariamente novas facetas de seu pai, mais rural e apegado à terra do que urbano, mais materialista e concreto do que sua mulher. Ana, movida por seu senso das aparências e da representação social, sonha em ascensão e grandeza. O que pode se reinterpretar como uma forma de alienação, de submissão aos modelos culturais de seus antigos mestres. Ao contrário, a rusticidade de Balila torna-se simplicidade na segunda narrativa, virtude que vai de par com as faculdades de adaptação que demonstra, por sua vez, o filho. De maneira que o destino trágico de Ana, que provém também da dureza e da rigidez da personagem, em parte atribuíveis às provações da vida, é feito de rupturas das quais o alcoolismo é a expressão mais dolorosa. Ao contrário, os altos e baixos da trajetória de Ciro conferem a ele uma dimensão picaresca quase à beira do cômico. 
[7] Resumo de Ana, pp. 74-5 e 107-9.

[8] Ibidem,p.109.
Naturalmente, o narrador torna-se uma caixa de ressonância dessas clivagens, tanto que o laço familiar mais frouxo que o prende a seu tio será compensado por breves mas esclarecedores encontros "casuais". Num deles, surpreendendo seu sobrinho perto do bar onde trabalha, Ciro o convida a voltar para casa numa atitude paternal e generosa ( $e$ lhe passa furtivamente alguns trocados); inversamente, na praça do canhão, é o narrador que, já adulto, partilha com seu tio aquilo que sabe da história da cidade 7 . Menos implicada, a narração inventa seus momentos afetivos e de proximidade que contribuem para legitimaro carisma que as últimas páginas do livro reconhecem ao tio.

Dito de outro modo, o texto é feito de alternância de posições, de contrapontos, que conferem a uma narrativa aparentemente simples e linear uma espessura e uma complexidade próprias. A proximidade afetiva do narrador com sua avó (por intermédio de dona Lazinha) atenua a distância histórica que os separa; e, pelo contrário, sua concomitância temporal com Ciro permite reintegrar o tio na genealogia materna. As lacunas a preencher são, aliás, menos o resultado dos recalcamentos de família do que os da história do país, como sugere a epígrafe do livro: "Fiéis servidores de nossa paisagem". Extraído de um longo poema de Carlos Drummond de Andrade intitulado "Os bens e o sangue", essas palavras designam - entre aquilo que uma família tradicional de Minas transmite de geração a geração: a terra, os casarões, os móveis, e também os escravos - a criadagem, e mais amplamente os atores obscuros da história nacional, anônimos, sem títulos, indignos de uma memória e da posteridade.A epígrafe adquire todo o seu alcance hermenêutico se relacionada com a cena aparentemente lateral da praça do canhão, perto do final do livro. A alguns passos de um vestígio de uma revolta abortada opondo a cidade de Sorocaba a São Paulo, ou seja, a oligarquia local às forças federalistas, o narrador conta com prazer a seu tio a história do herói do lugar, o general brigadeiro Rafael Tobias de Aguiar. A passagem é concluída com essa observação: "Tenho presente que o comentário que fez sobre o relato, ao levantar-se da mureta com as duas sacolas na mão, foi que um dos prejuízos que sentia por não ter podido estudar é que não conhecia o único lugar onde havia vivido"8.

Tudo funciona aqui simetricamente invertido: o general Tobias não é herói senão em virtude de uma história oficial algo falsificada. À testa de uma tropa que jamais lutara, é logo um chefe vencido, fugitivo, prisioneiro, e à morte finalmente pouco gloriosa. $\mathrm{O}$ monumento encarregado de honrar sua memória é o canhão que domina a cidade, que na realidade jamais disparou um tiro sequer. Impotência e vaidade das elites. $O$ verdadeiro herói da cidade, que a fez existir com seus companheiros de infortúnio, é na verdade Ciro. Ora, ele não tem direito a nenhum nome dessas ruas que a narrativa mencio- 
na com tanta insistência. Ela endossa a versão oficial com o mesmo respeito, a mesma fascinação, semelhantes à demonstrada por sua mãe diante da decoração luxuosa do Teatro Municipal de São Paulo ou os falbalás do Alhambra de Sorocaba. É somente nesse sentido que ele se crê desapossado de "sua" história: não por falta de reconhecimento do que realizou, mas por sua própria ignorância e pouca instrução. Longe de aspirar a qualquer tipo de celebridade, de reivindicar qualquer consideração, ele aceita e interioriza a humildade que a história lhe destina. Mas este "saber" do qual as Grandes Narrativas se auto-investiram, este saber que o narrador passa a assumir na sua explicação e pelo qual faz sentido a paisagem, a praça do canhão, é feito de heroísmo indevido, usurpado. Ciência enganosa, ilusória, que acaba onde começa uma outra lição, implícita, na qual o leitor poderá completar a reescritura, restabelecer os valores, as verdadeiras hierarquias. Deste ponto de vista, Resumo de Ana surge enfim como um tipo de epopéia em tom menor. Mini-epopéia popular confederando milhares de destinos anônimos, encarnados, "resumidos" em duas vidas, a de Ana e a de Ciro. Menor, não pela desimportância, mas pela tonalidade renitente à efusão e às exaltações, usadas e abusadas pelo discurso da impostura.

O motor da luz radicaliza tal desconfiança. O narrador único não é mais suficiente para cimentar uma narrativa por demais heteróclita, desarticulada. Nele se emaranham um enxame de personagens e planos temporais: o dos ancestrais, da história de Simplício Almino de Alencar, de Noemi e Xande, do primo Valdério, do Gordo... Intrigas, espaços, imbricam-se, mesclam-se: Crato, Recife, Brasília, Argel, Paris, Nova York... E como se não bastassem tais justaposições e vai-evéns, cada capítulo (nada menos que vinte para uma narrativa de pouco mais de sessenta páginas, o que formaliza a própria fragmentação) é precedido de epígrafes mais ou menos longas, recheado de citações discretamente assinaladas, quando não é constituído pela inserção em bruto de um recorte de jornal ou de páginas arrancadas ao diário de tia Noemi, no qual a redação ingênua e inábil contrasta, por exemplo, com as circunlocuções refinadas do primeiro capítulo. Tantas vozes, mesmo que auxiliem a circunscrever sua família "literária", acompanham a instabilidade do "eu" narrativo com o qual entram em concorrência, disputando a palavra e ameaçando a homogeneidade do olhar e do tom. Sua multiplicidade e sua diversidade correm o risco de tornar indiscernível qualquer direção da narrativa, seu próprio sentido. Já não existiria mais centro, agora plural, disseminado? Não mais fronteiras, circunferência?

Longe da narrativa sabiamente arquitetada de Relato de um certo oriente ou da linearidade enganosa de Resumo de Ana, este livro, no uníssono de seu caos narrativo feito de colagens de pequenas cenas, 
conta uma sucessão de fracassos: amores não partilhados, projetos abortados de modernização industrial por parte de Xande, a democratização de Pernambuco interrompida pelo golpe de Estado, a ineficácia do direito contra a força arbitrária, os esforços vãos de proteção de um pequeno camponês contra os caprichos de um coronel, a resistência da luta armada, rapidamente infiltrada e desmantelada pela ditadura, talvez mesmo graças às traições de seus supostos "heróis" como o Cabo Anselmo. Mesmo a anistia de 1980 não permite aos antigos combatentes clandestinos refazer a própria vida, já que não puderam mudar as alheias: essa esperança foi por sua vez ceifada por sórdidos acertos de conta pós-guerrilha. Promessas não cumpridas de um futuro radioso, impulsos podados pelo autoritarismo e pelo conservadorismo ambientes, forças inerciais do passado e das mentalidades arcaicas: "Agora tornara-se claro que o futuro não se organizara em torno de nós"9.

O livro não seria ao final senão uma litania de veleidades, derrotas, ilusões, tingida de um desencanto generalizado, se o leitor não sentisse apesar de tudo a cada instante uma faísca de sonho, de vida, ao menos uma capacidade de indignação: o derrisório e entretanto irreprimível "motor" da existência, a chama vacilante de uma "luz". Como se explica então que esse livro, de resto tão sombrio, escape ao niilismo e ao desespero? Por uma resistência nova comparável àquela que anima as personagens de Samuel Beckett, para os quais a palavra serve tanto para proclamar a progressão do nada como para reagir a seu apelo. Recorrendo a referências mais familiares a José Almino, é como se Machado de Assis viesse aqui modular José Lins do Rego, como se a nostalgia do tempo perdido fosse temperada com ceticismo. Pois $O$ motor da luz reata-se claramente com a tradição pernambucana de uma literatura da decadência, da qual seu autor conhece os valores, a poética e a retórica. Mas ele não se limita a essa literatura. Pelo contrário, ele renova o gênero ao recusar toda e qualquer idealização, mesmo a de uma era dourada. Isso é particularmente claro na relação que o livro mantém com a literatura. Ela pode afagar o narcisismo de um jovem aspirante à carreira de escritor, se comprazer com as patotas literárias, se alimentar de histrionismo, de fatuidade e pedantismo, como as tagarelices peremptórias do Gordo, ela pode constituir um refúgio estéril, uma carapaça resignando-se a uma pequena dose de real e mesmo dele se protegendo, ela pode diluir a voz de um "autor" no infinito jogo de espelhos das citações. Enfim, pode-se pagar com a falsa moeda da eloqüência, mesmo nas precauções contra as voltas e reviravoltas da autocomplacência. Não importa. É ela também, como testemunha o resultado do livro, que oferece uma expressão à dor, ao sentimento de vazio e de anulação; ela, que constitui a possibilidade de um avanço, de uma sublimação, de um desfecho; ela que, notadamente, pelas cita- 
ções, possui o abre-te-sésamo das estações sucessivas de nossa existência. Não exatamente saída, mas passo inicial, estado de vigilância, ato, reação, aprumo.

Para JoséAlmino, a citação não tem nada de exibição pós-moderna, pastiche desistoricizado ou mimetismo neutro ${ }^{10}$ : nua ecrua, ela é quase brutal. Depende de o leitor encontrar nelas os harmônicos. Oscilando entre o elegíaco e os balanços desabusados, ele não é, com efeito, solicitado somente para reconstituir os pontos de referência espácio-temporais faltantes, restabelecer as conexões lógicas ausentes, mas para interpretar essa trama de vozes, amontoado pungente à imagem dessa geração sacrificada, esmagada. A citação aninha-se nos interstícios de capítulos modestos e lacônicos, introduz-se nas brechas abertas pelas elipses da narrativa. Ora, feito coro, que reúne autores reconhecidos ou consagrados, de Montaigne a Naipaul, mas também modestos poetas pernambucanos e os cadernos de Noemi, tem um alcance incrivelmente democrático: nele figuram mais os textos do que propriamente autoridades, "nomes", valores estabelecidos. E neles se percebe que a ingenuidade de certas escritas tem um vigor insuspeito.

As referências literárias de Relato de um certo oriente respondem a uma lógica bem diferente. Elas são discretas, alusivas, como a catléia de Proust, a terceira margem de Guimarães Rosa ou o papagaio de Flaubert; elas não serão identificadas senão pelos iniciados. No limite inessenciais para a compreensão da diegese, elas participam entretanto dos efeitos matizantes do interculturalismo, caros a uma linhagem igualmente ilustrada pelos estudos de Edward Saïd. À imagem das paisagens descobertas pelo ancestral, Hanna: "rios de superfície tão vasta que pareciam um espelho infinito; a pele furta-cor de certo réptil" ${ }^{11}$; mas os brilhos do mundo acabam por se assemelhar, as viagens revelam-se mais interiores do que geográficas, as praias descobertas pelos levantinos os reconduzem sempre a seu porto de amarração: toda praia, todo litoral os atraem, em qualquer lugar do mundo onde se encontrem, mas as águas que vêem e que navegam são sempre as do Mediterrâneo ${ }^{12}$.

Quanto à inscrição do patrimônio literário em Resumo de Ana, ele surge à imagem e semelhança da sobriedade do texto e quase que se limita à citação já mencionada do poeta Drummond. Todavia vemos aparecerem incidentalmente nomes como Paulo Emilio Sales Gomes ou Oswald de Andrade; explicitamente, menos remetendo a seus escritos que a título de personagens históricas. A família do primeiro possuía em Sorocaba uma fábrica na qual irá trabalhar a jovem Lazinha, no final da primeira novela. E os patrões de Anita, a última companheira de Ciro, freqüentam ocasionalmente os círculos modernistas de São Paulo.A menção é de caráter econômico, designando no entanto novamente um círculo de afinidades.
[10] Cf. sobre o assunto as análises de Jameson, Fredric. Pós-modernismo: a lógica cultural do capitalismo tardio. São Paulo:Ática, 1996.

[11] Relato de um certo oriente, p.71.

[12] Ibidem, p. 76 . 
Recebido para publicação

em 12 de outubro de 2008 .

\section{NOVOS ESTUDOS}

CEBRAP

84 , julho 2009

pp. 251-261
A cada vez, finalmente, a literatura, parti pris da escrita e elemento de referência, tem uma dupla finalidade. Em primeiro lugar, ela reorganiza a experiência para torná-la mais legível.Aquilo que a ficção faz perder em precisão referencial no trabalho da "memória", se ganha em virtualidade significante. Mas ao mesmo tempo essa reorganização preserva-se de reduzir e de simplificar a complexidade do vivido. Saída do caos e do informe, ela deve restituir as contradições, os "buracos", sem o quê ela não é mais literatura, mas livro de receitas. Grande parte do seu destino se joga, acreditamos, nessa intersecção paradoxal, à qual corres ponde o reencontro não menos decisivo de um escritor e de seu leitor, de um texto e de uma leitura. Por isso a literatura não é interpretação, mas potência interpretativa: virtude potencial, em suspensão, à espera. O que (nos) espera? Sua "ilegibilidade", aquilo que não se oferece à primeira abordagem, não se entrega, o que pega e agarra, a parte sediciosa abandonada aos que virão: o lugar do impensado do texto, que faz de sua maneira de pensar um pensamento insubstituível, sem igual.

MiCHel RiAUdel é maître de conférence na Universidade de Poitiers. Tradutor, ele dirigiu o número da revista Europe sobre a literatura brasileira contemporânea, com Pierre Rivas (nov. 2005), organizou o catálogo bibliográfico France Brésil (La Documentation Française, 2005). É autor de uma tese de doutorado sobre intertextualidade, tradução e criação na obra de Ana Cristina Cesar. 